Proceedings

\title{
Development and Application of an LC-MS/MS Method for Identification of Polyphenols in Propolis Extract ${ }^{\dagger}$
}

\author{
Madalina Maria Nichitoi 1,*, Teodor Costache 2, Ana Maria Josceanu 3, Raluca Isopescu 4, \\ Gabriela Isopencu ${ }^{4}$ and Vasile Lavric ${ }^{4}$ \\ 1 Doctoral School "Applied Chemistry and Materials Sciences", University Politehnica of Bucharest, \\ 1-7 Polizu Street, 011061 Bucharest, Romania \\ 2 Research Center for Instrumental Analysis SCIENT, 1E Petre Ispirescu Street, 077167 Tâncăbești, Ilfov, \\ Romania; teodor.costache@scient.ro \\ 3 Department of Analytical Chemistry and Environmental Engineering, University Politehnica of Bucharest, \\ 1-7 Polizu Street, 011061 Bucharest, Romania; a_josceanu@chim.upb.ro \\ 4 Department of Chemical and Biochemical Engineering, University Politehnica of Bucharest, \\ 1-7 Polizu Street, 011061 Bucharest, Romania; r_isopescu@chim.upb.ro (R.I.); \\ g_isopencu@chim.upb.ro (G.I.); vasile.lavric@gmail.com (V.L.) \\ * Correspondence: maria.nichitoi@yahoo.com \\ † Presented at the Virtual Eurachem Workshop 2020 - "Quality Assurance for Analytical Laboratories in the \\ University Curriculum", 14-15 July 2020; Available online: https://eurachem2020.ro/.
}

Published: 24 September 2020

\begin{abstract}
We identified and quantified by LC-MS/MS 11 (quercetin, galangin, pinocembrin, kaempferol, vanillin, chrysin, gallic acid, $p$-coumaric acid, trans-ferulic acid, caffeic acid, and caffeic acid phenethyl ester) out of the 21 polyphenolic compounds we looked for in ethanolic ( $25 \%$ and $50 \%)$ and aqueous propolis extracts by comparison with standards and literature data.
\end{abstract}

Keywords: propolis; LC-MS; polyphenolic compounds

\section{Introduction}

The purpose of this study is to identify the most common polyphenols found in Romanian propolis and quantify their levels in various hydroalcoholic extracts. In this regard, we have worked to develop an efficient and reliable method of analysis.

LC-MS is the method of choice in various environmental, pharmaceutical, and biochemical laboratories due to its selectivity, sensitivity, and versatility [1].

\section{Materials and Methods}

The LC-MS/MS analysis was carried out using a Q Trap 5500 Triple Quadrupole Mass spectrometer from Sciex with Electrospray Ionization (ESI)/Turbo Ion Spray mode. In the chromatographic analysis, a Synergi C18 (Fusion-RP $80 \AA$, $50 \times 2 \mathrm{~mm}$, particle size of $4 \mu \mathrm{m}$ ) column (Phenomenex Inc., Torrance, CA, USA) was used with an injection volume of $5 \mu \mathrm{L}$. The solvents used were (A) formic acid (0.5\%) and (B) methanol. Gradient elution ranged from $2 \%$ to $98 \%$ B at $30{ }^{\circ} \mathrm{C}$, and elution flow was set at $900 \mu \mathrm{L} / \mathrm{min}$. The elution time was $20 \mathrm{~min}$. The ionization source temperature of the MS was $500{ }^{\circ} \mathrm{C}$; mass spectra were recorded in the negative ion mode, between $50 \mathrm{~m} / \mathrm{z}$ and $500 \mathrm{~m} / \mathrm{z}$ using nitrogen as the collision gas. The pressure of the gas flux to the nebulizer was set at 1000 psi. 
ACS standards (quercetin, pinocembrin, galangin, kaempferol, vanillin, chrysin, gallic acid, $p$-coumaric acid, $t$-ferulic acid, caffeic acid, and caffeic acid phenethyl ester (CAPE)) were used to prepare individual $500 \mu \mathrm{g} / \mathrm{mL}$ stocks in ethanol. A mixed working standard, $10 \mu \mathrm{g} / \mathrm{mL}$ solution in ethanol, was obtained by appropriate dilution of individual stocks. Ethanol calibration solutions were prepared in a $0.08-5 \mu \mathrm{g} / \mathrm{mL}$ range. Automatic pipettes and class A volumetric glass flasks were used.

All solvents (ethanol, methanol, formic acid) were analytical grade and used without further purification.

Propolis extracts were prepared according to the procedure presented previously [2].

For the analysis of the samples, the type of targeted MS/MS scan was used, in which a selected ion is monitored on Q1 and a chosen fragment of the molecular ion on Q3. The sequence of analysis consisted of the injection from polypropylene filtration plates of the 2 blanks that contain mobile phase A, 7 mix solutions of polyphenols in the order of increasing the concentration $0.08,0.1,0.5,1$, 2, 3, $5 \mu \mathrm{g} / \mathrm{mL} ; 2$ blanks, 9 aqueous samples, 2 blanks, 1 calibration solution, 2 blanks, $925 \%$ ethanolic samples, 2 blanks samples, 1 calibration solution, 2 blanks, $950 \%$ ethanolic samples, 2 blanks samples, 1 calibration solution, 2 blanks, twice consecutive reinjection of a $25 \%$ ethanolic sample, 2 blanks.

\section{Results and Discussion}

Experimental parameters for each analyte were identified by direct injection in the MS module of individual standards, in the $0.001-0.1 \mu \mathrm{g} / \mathrm{mL}$ concentration range, resulting in the corresponding productions. Individual characteristics are collected in Table 1.

Table 1. MS experimental characteristics of the investigated compounds.

\begin{tabular}{ccccccc}
\hline Compound & $\begin{array}{c}\text { Parent Ion, } \\
\text { Da }\end{array}$ & $\begin{array}{c}\text { Precursor Ion, } \\
\text { Da }\end{array}$ & $\begin{array}{c}\text { DPa, } \\
\text { V }\end{array}$ & $\begin{array}{c}\mathbf{E P}^{\mathbf{b}}, \\
\mathbf{V}\end{array}$ & $\begin{array}{c}\mathbf{C E}^{\mathbf{c}}, \\
\mathbf{e V}\end{array}$ & $\begin{array}{c}\text { CXPd, } \\
\mathbf{V}\end{array}$ \\
\hline Caffeic acid & 178.9 & 134.9 & -70 & -10 & -22 & -13 \\
\hline$p$-Coumaric acid & 162.9 & 118.9 & -60 & -10 & -22 & -9 \\
\hline Gallic acid & 168.8 & 124.9 & -65 & -10 & -20 & -11 \\
\hline$t$-Ferulic acid & 192.9 & 133.8 & -70 & -10 & -22 & -11 \\
\hline Kaempferol & 284.9 & 92.9 & -130 & -10 & -54 & -7 \\
\hline Quercetin & 300.9 & 135.8 & -120 & -10 & -28 & -11 \\
\hline Chrysin & 253 & 208.9 & -145 & -10 & -20 & -17 \\
\hline Pinocembrin & 255 & 212.8 & -120 & -10 & -28 & -28 \\
\hline Vanillin & 150.9 & 135.8 & -60 & -10 & -18 & -9 \\
\hline CAPE & 283 & 135 & -120 & -10 & -72 & -17 \\
\hline Gallangin & 268.9 & 168.8 & -105 & -10 & -36 & -11 \\
\hline
\end{tabular}

a Declustering potential, ${ }^{\mathrm{b}}$ entrance potential, ${ }^{\mathrm{c}}$ collision energy, ${ }^{\mathrm{d}}$ collision cell exit potential.

Selectivity has been investigated in terms of relative standard deviations of the retention times [3]. As data in Table 2 demonstrate, they did not exceed $0.21 \%$.

Table 2. Method specificity.

\begin{tabular}{ccc}
\hline Analyte Name & Retention Time, min & Relative Standard Deviation, $\mathbf{\%}$ \\
\hline Gallic Acid & 0.262 & 0.020 \\
\hline Caffeic Acid & 1.88 & 0.080 \\
\hline Vanillin & 2.04 & 0.045 \\
\hline$p$-Coumaric Acid & 2.32 & 0.024 \\
\hline$t$-Ferulic Acid & 2.66 & 0.090 \\
\hline Quercetin & 4.13 & 0.210 \\
\hline Kaempferol & 4.64 & 0.070 \\
\hline Pinocembrin & 4.86 & 0.120 \\
\hline CAPE & 5.19 & 0.080 \\
\hline Chrysin & 5.25 & 0.010 \\
\hline Galangin & 5.26 & 0.050
\end{tabular}


Calibration curves were obtained for the $0.08-5 \mu \mathrm{g} / \mathrm{mL}$ concentration range for all analytes of interest. Experiments run at seven concentration levels, using at least two replicate injections for each concentration level, gave linear regressions in terms of peak area, characterized by correlation coefficients larger than 0.9988 , except chrysin, with a determination coefficient of 0.9822 , as shown in Table 3. The calibration curve for $t$-ferulic acid is presented in Figure 1.

Table 3. Calibration parameters.

\begin{tabular}{cccc}
\hline Analyte & Intercept & Slope & $\mathbf{R}^{\mathbf{2}}$ \\
\hline Quercetin & $1.35 \times 10^{4}$ & $1.84 \times 10^{6}$ & 0.9998 \\
\hline Chrysin & $7.09 \times 10^{3}$ & $4.09 \times 10^{4}$ & 0.9822 \\
\hline Vanillin & $2.83 \times 10^{4}$ & $1.07 \times 10^{6}$ & 0.9994 \\
\hline Pinocembrin & $4.63 \times 10^{4}$ & $1.29 \times 10^{6}$ & 0.9990 \\
\hline Kaempferol & $2.16 \times 10^{3}$ & $1.60 \times 10^{5}$ & 0.9995 \\
\hline CAPE & $1.51 \times 10^{4}$ & $1.29 \times 10^{5}$ & 0.9988 \\
\hline$t$-Ferulic Acid & $2.26 \times 10^{4}$ & $1.26 \times 10^{6}$ & 1 \\
\hline$p$-Coumaric Acid & $2.83 \times 10^{5}$ & $1.17 \times 10^{7}$ & 0.9992 \\
\hline Gallic Acid & $7.90 \times 10^{4}$ & $5.99 \times 10^{6}$ & 0.9991 \\
\hline Caffeic Acid & $1.51 \times 10^{5}$ & $9.99 \times 10^{6}$ & 0.9995 \\
\hline Galangin & $9.84 \times 10^{3}$ & $6.25 \times 10^{5}$ & 0.9988 \\
\hline
\end{tabular}

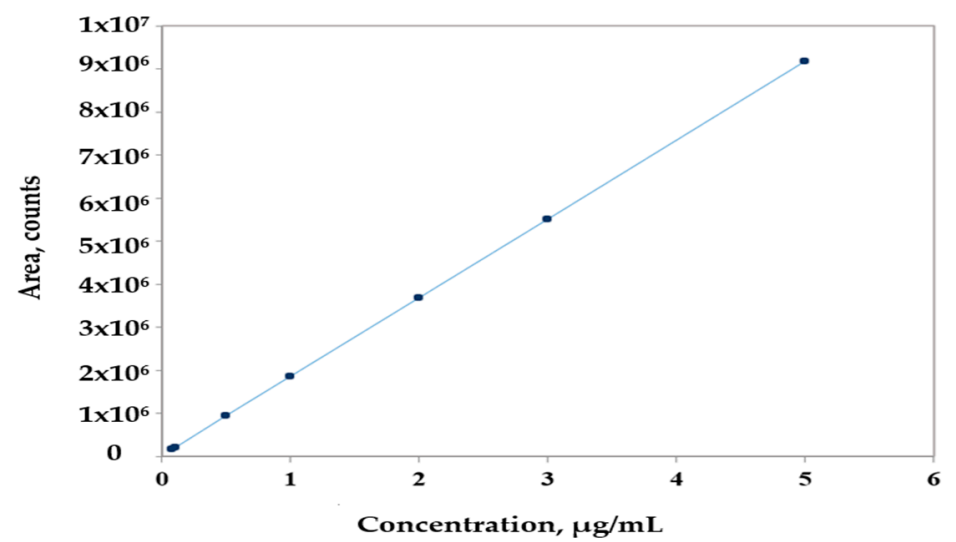

Figure 1. Calibration curve for $t$-ferulic acid.

Limit of quantitation, LOQ, and limit of detection, LOD, as shown in Table 4, were evaluated as per International Council for Harmonisation of Technical Requirements for Pharmaceuticals for Human Use Guideline [3,4].

Table 4. Limit of quantitation (LOD) and limit of detection (LOQ) calculated for analytes of interest.

\begin{tabular}{ccc}
\hline Analyte & LOD, $\boldsymbol{\mu g} / \mathbf{m L}$ & LOQ, $\boldsymbol{\mu g} / \mathbf{m L}$ \\
\hline Quercetin & 0.07 & 0.17 \\
\hline Chrysin & 0.23 & 0.69 \\
\hline Vanillin & 0.09 & 0.26 \\
\hline Pinocembrin & 0.12 & 0.37 \\
\hline Kaempferol & 0.08 & 0.24 \\
\hline CAPE & 0.17 & 0.51 \\
\hline$t$-Ferulic Acid & 0.01 & 0.03 \\
\hline$p$-Coumaric Acid & 0.16 & 0.49 \\
\hline Gallic Acid & 0.17 & 0.52 \\
\hline Caffeic Acid & 0.12 & 0.30 \\
\hline Galangin & 0.18 & 0.54
\end{tabular}


The method was applied for the analysis of Romanian propolis extracts. Figures 3 and 4 show typical LC-MS/MS chromatograms. The quantified levels of polyphenolics are collected in Table 5.

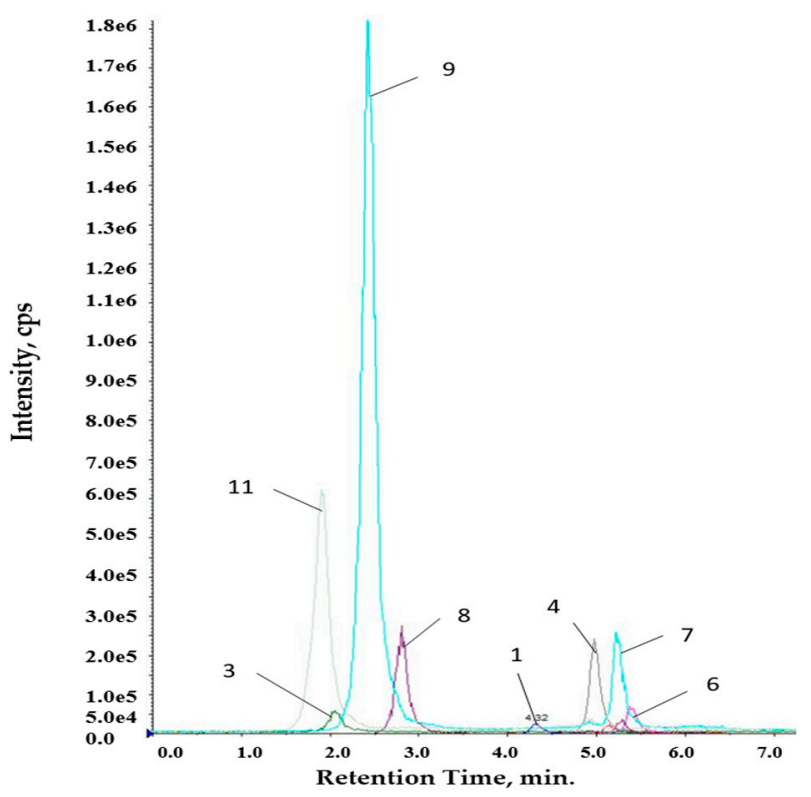

Figure 2. Chromatogram for ethanolic extract.

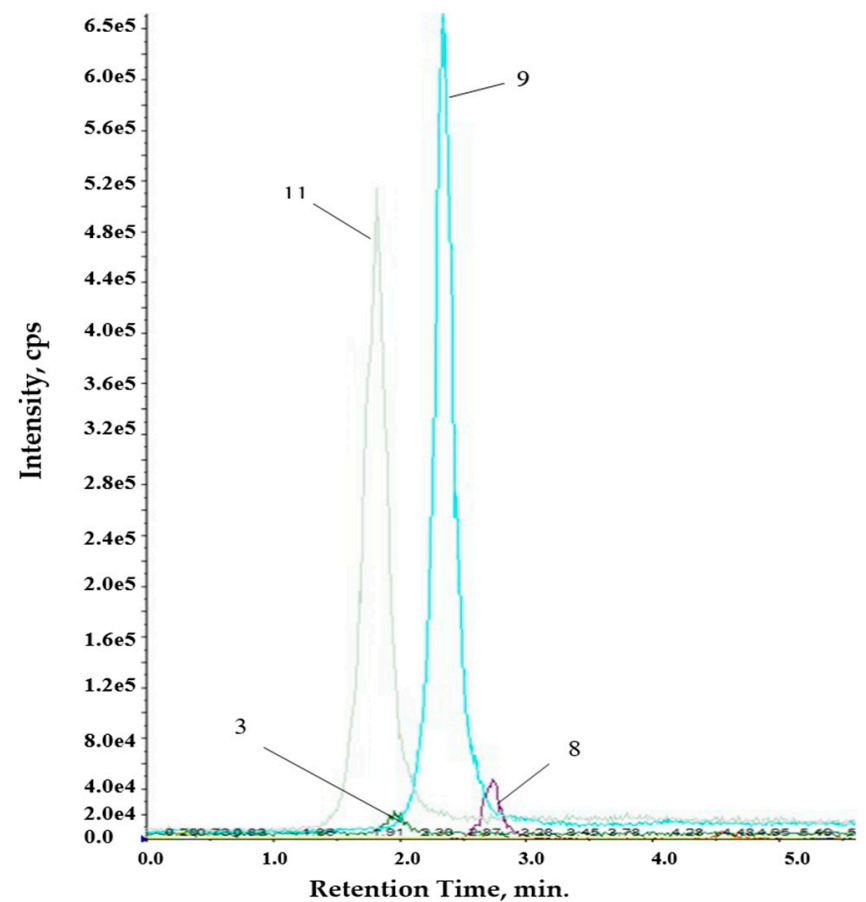

Figure 3. Chromatogram for aqueous extract.

The polyphenols identified in the propolis under study fall into two categories: compounds that are not extracted in water (quercetin, chrysin, pinocembrin, kaempferol, galangin, CAPE) and compounds that are extracted both in water and ethanolic solutions ( $p$-coumaric acid, trans-ferulic acid, caffeic acid, vanillin). 
Table 5. Polyphenolics in ethanolic and aqueous extracts.

\begin{tabular}{cccccc}
\hline & Compound & \multicolumn{2}{c}{ Ethanolic Extract } & \multicolumn{2}{c}{ Aqueous Extract } \\
\hline \multirow{2}{*}{ Code } & \multirow{2}{*}{ Name } & Retention & Concentration, & Retention & Concentration, \\
\cline { 3 - 6 } & & Time, $\mathbf{m i n}$ & $\mu \mathrm{g} / \mathrm{mL}$ & Time, min & $\mu \mathrm{g} / \mathbf{m L}$ \\
\hline 1 & Quercetin & 4.311 & 0.834 & - & - \\
\hline 2 & Chrysin & - & - & - & - \\
\hline 3 & Vanillin & 2.040 & 3.589 & 1.964 & 0.292 \\
\hline 4 & Pinocembrin & 4.978 & 10.50 & - & - \\
\hline 5 & Kaempferol & 4.699 & 0.990 & - & - \\
\hline 6 & Galangin & 5.389 & 6.781 & - & - \\
\hline 7 & CAPE & 5.276 & 4.579 & - & - \\
\hline 8 & $t$-Ferulic Acid & 2.808 & 13.26 & 2.744 & 0.794 \\
\hline 9 & $p$-Coumaric Acid & 2.427 & 10.80 & 2.340 & 1.261 \\
\hline 10 & Gallic Acid & - & - & - & - \\
\hline 11 & Caffeic Acid & 1.910 & 4.873 & 1.821 & 1.330 \\
\hline
\end{tabular}

\section{Conclusions}

The system used for the analysis of phenolic compounds in propolis extracts consisted of an Ultra High-Performance Liquid Chromatograph coupled with a 5500 Triple Quadrupole Mass Spectrometer and the mass spectra were recorded in the negative ion mode.

Calibration curves were obtained by injecting mixtures of exactly known concentrations $(0.08$; $0.1 ; 0.5 ; 1 ; 2 ; 3 ; 5 \mu \mathrm{g} / \mathrm{mL}$ ), resulting in correlation coefficients larger than 0.9988 , except for chrysin.

Relative standard deviations of the retention times were below $0.2 \%$. The values corresponding to the detection limits were between 0.01 and $0.23 \mu \mathrm{g} / \mathrm{mL}$ and limits of quantitation had values in the range $0.03 \mu \mathrm{g} / \mathrm{mL}$ (for $t$-ferulic acid) $-0.69 \mu \mathrm{g} / \mathrm{mL}$ (chrysin).

The use of the LC-MS analysis method proposed proved effective in quantifying 11 polyphenolics in aqueous and ethanolic extracts of propolis.

Funding: This work was supported by the Research Center for Instrumental Analysis SCIENT, 1E Petre Ispirescu Street, 077167 Tâncăbești, Ilfov, Romania. Also, the authors would like to thank project Work-based entrepreneurial learning systems for Ph.D. and postdoctoral students (SIMBA), MySMIS 124705, co-financed by the European Social Fund (ESF), through the Human Capital Operational Program (POCU)/ 51668/09.07.2019.

Conflicts of Interest: The authors declare no conflict of interest.

\section{References}

1. Hokkanen, J. Liquid chromatography mass spectrometry of bioactive secondary metabolites- in vivo and in vitro studies. Acta Universitatis Ouluensis a Scientiae Rerum Naturalium 606 University of Oulu Repository, Finland. 2013. Available online: http://jultika.oulu.fi/files/isbn9789526200897.pdf (accessed on 1 September 2020).

2. Nichitoi, M.M.; Josceanu, A.M.; Isopescu, R.D.; Isopencu, G.; Lavric, V. Romanian propolis extracts: Characterization and statistical analysis and modelling. UPB. Sci. Bull. Series B 2019, 81, 149-162.

3. Josceanu, A.M.; Postelnicescu, P.; Dumitrescu, A.M. Validation of an Ion Chromatographic Method for Lead and Cooper Quantification. in Proceedings of the 36th International Conference of Slovak Society of Chemical Engineering, Tatranske Matliare, Slovakia, 24-28 May 2010; p. 471, ISBN 978-80-227-3290-1.

4. International Council for Harmonisation of Technical Requirements for Pharmaceuticals for Human Use $(\mathrm{ICH}), \quad$ 2 (R1)-Validation of analytical procedures text and methodology, Available online: https://www.ich.org/ (accessed on 8 July 2020).

(C) 2020 by the authors. Licensee MDPI, Basel, Switzerland. This article is an open access article distributed under the terms and conditions of the Creative Commons Attribution (CC BY) license (http://creativecommons.org/licenses/by/4.0/). 